\title{
Exploring the light-induced dynamics in solvated metallogrid complexes with femtosecond pulses across the electromagnetic spectrum
}

Naumova, Maria A; Kalinko, Aleksandr; Wong, Joanne W L; Alvarez Gutierrez, Sol Laura; Meng, Jie; Liang, Mingli; Abdellah, Mohamed; Geng, Huifang; Lin, Weihua; Kubicek, Katharina

Total number of authors:

31

Published in:

The Journal of Chemical Physics

Link to article, DOI:

$10.1063 / 1.5138641$

Publication date:

2020

Document Version

Publisher's PDF, also known as Version of record

Link back to DTU Orbit

Citation (APA):

Naumova, M. A., Kalinko, A., Wong, J. W. L., Alvarez Gutierrez, S. L., Meng, J., Liang, M., Abdellah, M., Geng, H., Lin, W., Kubicek, K., Biednov, M., Lima, F., Galler, A., Zalden, P., Checchia, S., Mante, P-A., Zimara, J., Schwarzer, D., Demeshko, S., ... Canton, S. E. (2020). Exploring the light-induced dynamics in solvated metallogrid complexes with femtosecond pulses across the electromagnetic spectrum. The Journal of Chemical Physics, 152(21), [214301]. https://doi.org/10.1063/1.5138641

\section{General rights}

Copyright and moral rights for the publications made accessible in the public portal are retained by the authors and/or other copyright owners and it is a condition of accessing publications that users recognise and abide by the legal requirements associated with these rights.

- Users may download and print one copy of any publication from the public portal for the purpose of private study or research.

- You may not further distribute the material or use it for any profit-making activity or commercial gain

- You may freely distribute the URL identifying the publication in the public portal 


\section{Exploring the light-induced dynamics in solvated metallogrid complexes with femtosecond pulses across the electromagnetic spectrum}

Cite as: J. Chem. Phys. 152, 214301 (2020); https://doi.org/10.1063/1.5138641

Submitted: 14 November 2019 . Accepted: 19 March 2020. Published Online: 01 June 2020

Maria A. Naumova (D), Aleksandr Kalinko, Joanne W. L. Wong, Sol Alvarez Gutierrez, Jie Meng, Mingli Liang $\mathbb{D}^{\mathrm{D}}$, Mohamed Abdellah, Huifang Geng, Weihua Lin, Katharina Kubicek, Mykola Biednov, Frederico Lima, Andreas Galler, Peter Zalden, Stefano Checchia (D), Pierre-Adrien Mante (D), Jennifer Zimara, Dirk Schwarzer (D), Serhiy Demeshko, Vadim Murzin, David Gosztola (D), Martin Jarenmark, Jianxin Zhang, Matthias Bauer, Max Latevi Lawson Daku (D), Dmitry Khakhulin, Wojciech Gawelda, Christian Bressler, Franc Meyer (D), Kaibo Zheng, and Sophie E. Canton (D)

\section{COLLECTIONS}

Paper published as part of the special topic on Ultrafast molecular sciences by femtosecond photons and electrons

Note: This paper is part of the JCP Special Topic on Ultrafast Molecular Sciences by Femtosecond Photons and Electrons.

F This paper was selected as Featured
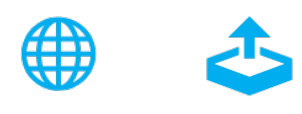

\section{ARTICLES YOU MAY BE INTERESTED IN}

Time reversal symmetry breaking and odd viscosity in active fluids: Green-Kubo and NEMD results

The Journal of Chemical Physics 152, 201102 (2020); https://doi.org/10.1063/5.0006441

Solvated iron metallogrid complex exhibits reversible photocycle

Scilight 2020, 231101 (2020); https://doi.org/10.1063/10.0001326

Dalton Project: A Python platform for molecular- and electronic-structure simulations of complex systems

The Journal of Chemical Physics 152, 214115 (2020); https://doi.org/10.1063/1.5144298 


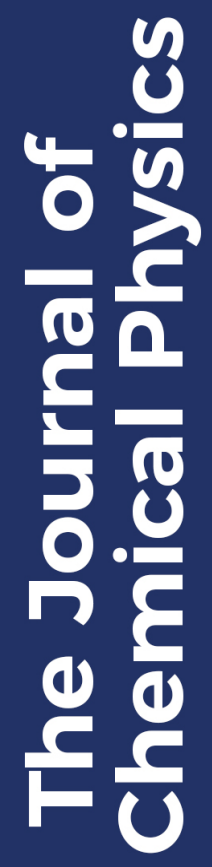

\section{Lock-in Amplifiers up to $600 \mathrm{MHz}$

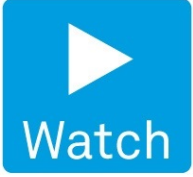

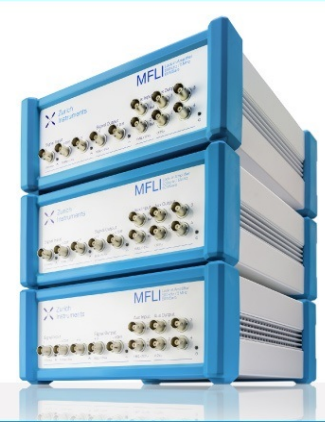

J. Chem. Phys. 152, 214301 (2020); https://doi.org/10.1063/1.5138641

152,214301

(c) 2020 Author(s). 


\section{Exploring the light-induced dynamics in solvated metallogrid complexes with femtosecond pulses across the electromagnetic spectrum ${ }^{\circ}$ )}

Cite as: J. Chem. Phys. 152, 214301 (2020); doi: 10.1063/1.5138641

Submitted: 14 November 2019 - Accepted: 19 March 2020 •

Published Online: 1 June 2020

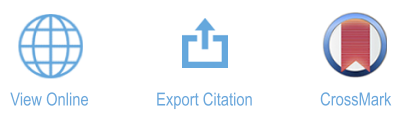

Maria A. Naumova, ${ }^{1}$ (D) Aleksandr Kalinko, ${ }^{1,2}$ Joanne W. L. Wong, ${ }^{3}$ Sol Alvarez Gutierrez, ${ }^{4}$ Jie Meng,

Mingli Liang, ${ }^{4}$ (D) Mohamed Abdellah, ${ }^{5,6}$ Huifang Geng, ${ }^{7}$ Weihua Lin, ${ }^{5}$ Katharina Kubicek, ${ }^{8}$ Mykola Biednov,

Frederico Lima, ${ }^{8}$ Andreas Galler, ${ }^{8}$ Peter Zalden, ${ }^{8}$ Stefano Checchia, ${ }^{9}$ (D) Pierre-Adrien Mante, ${ }^{5,}$

Jennifer Zimara, ${ }^{11, a)}$ Dirk Schwarzer, ${ }^{11}$ (D) Serhiy Demeshko, ${ }^{3}$ Vadim Murzin, ${ }^{1,12}$ David Gosztola,

Martin Jarenmark, ${ }^{14}$ Jianxin Zhang, ${ }^{15}$ Matthias Bauer, ${ }^{2}$ Max Latevi Lawson Daku, ${ }^{16}$ (D) Dmitry Khakhulin, ${ }^{8}$

Wojciech Gawelda, ${ }^{8,17}$ Christian Bressler, ${ }^{8,18}$ Franc Meyer, $^{3}$ (D) Kaibo Zheng, ${ }^{4,5}$ and Sophie E. Canton ${ }^{1,7, b)}$ (D)

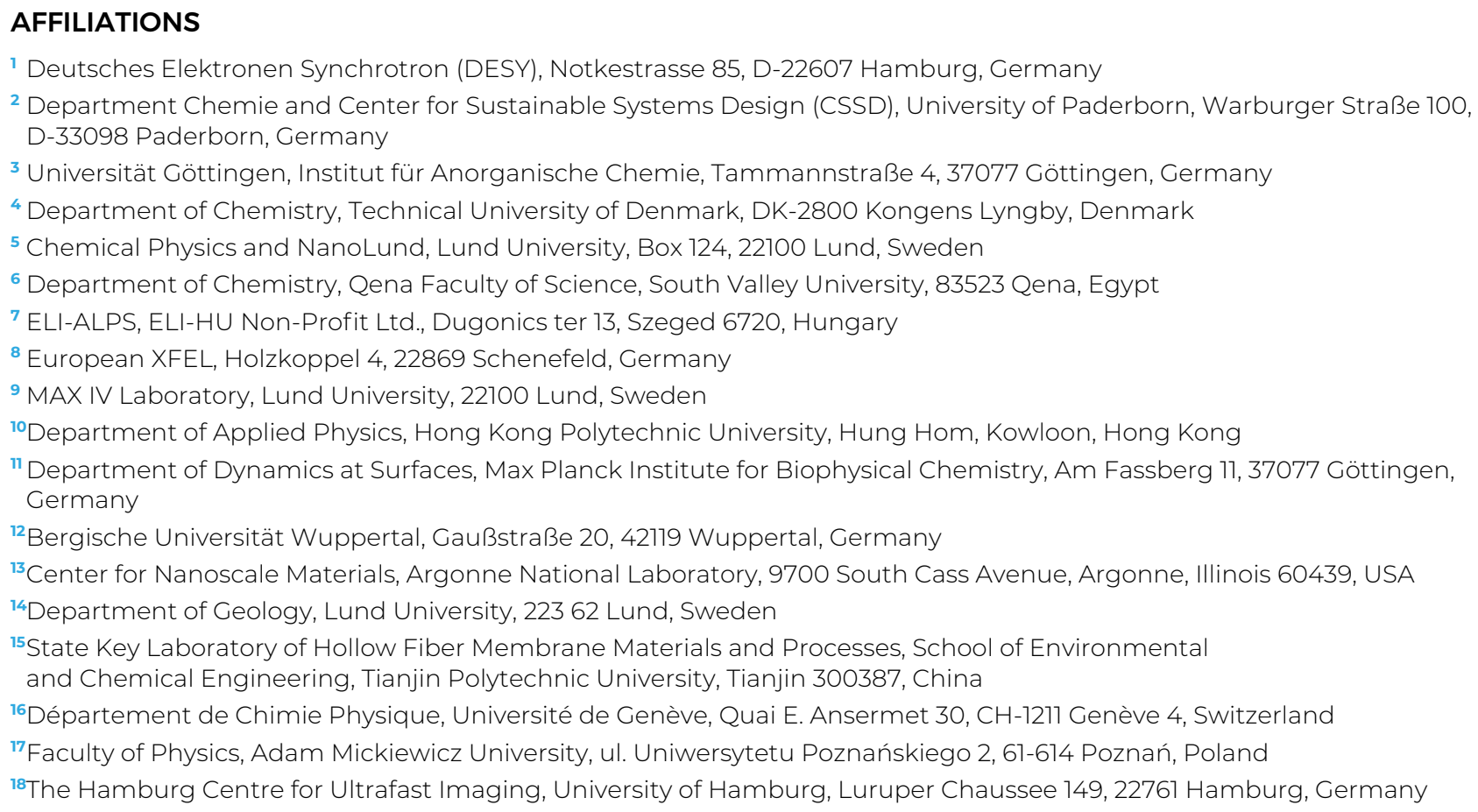

Note: This paper is part of the JCP Special Topic on Ultrafast Molecular Sciences by Femtosecond Photons and Electrons.

a) Present address: Laser-Laboratorium Göttingen e.V., Hans-Adolf-Krebs-Weg 1, Göttingen 37077, Germany.

b) Author to whom correspondence should be addressed: sophie.canton@eli-alps.hu

\section{ABSTRACT}

Oligonuclear complexes of $\mathrm{d}^{4}-\mathrm{d}^{7}$ transition metal ion centers that undergo spin-switching have long been developed for their practical role in molecular electronics. Recently, they also have appeared as promising photochemical reactants demonstrating improved stability. However, the lack of knowledge about their photophysical properties in the solution phase compared to mononuclear complexes is currently 
hampering their inclusion into advanced light-driven reactions. In the present study, the ultrafast photoinduced dynamics in a solvated $[2 \times 2]$ iron(II) metallogrid complex are characterized by combining measurements with transient optical-infrared absorption and $\mathrm{x}$-ray emission spectroscopy on the femtosecond time scale. The analysis is supported by density functional theory calculations. The photocycle can be described in terms of intra-site transitions, where the Fe ${ }^{\mathrm{II}}$ centers in the low-spin state are independently photoexcited. The FranckCondon state decays via the formation of a vibrationally hot high-spin (HS) state that displays coherent behavior within a few picoseconds and thermalizes within tens of picoseconds to yield a metastable HS state living for several hundreds of nanoseconds. Systematic comparison with the closely related mononuclear complex $\left[\mathrm{Fe}(\text { terpy })_{2}\right]^{2+}$ reveals that nuclearity has a profound impact on the photoinduced dynamics. More generally, this work provides guidelines for expanding the integration of oligonuclear complexes into new photoconversion schemes that may be triggered by ultrafast spin-switching.

Published under license by AIP Publishing. https://doi.org/10.1063/1.5138641

\section{INTRODUCTION}

Photoinduced spin-switching (PSS) in solvated $\mathrm{d}^{4}-\mathrm{d}^{7}$ transition metal (TM) complexes is a fundamental molecular process, which is driving a growing number of advanced technologies, including ion sensing, photocatalysis, and drug delivery (Kumar and Ruben, 2017; Halcrow, 2013). The vast majority of solvated TM compounds that operate through efficient PSS are mononuclear $\mathrm{Fe}^{\mathrm{II}}$ complexes that switch from the low-spin (LS) $\left(\mathrm{t}_{2 \mathrm{~g}}\right)^{6}{ }^{1} \mathrm{~A}_{1}$ state to the high-spin (HS) $\left(t_{2 g}\right)^{4}\left(e_{g}\right)^{2}{ }^{5} T_{1}$ state upon light irradiation. Despite definite success in laboratory settings, the efficiencies reported so far cannot yet meet the demands of chemical applications in real-life because of the limitations associated with rather restricted intramolecular distortions and photodecomposition. The prospect of overcoming these hurdles is currently spurring a significant synthetic effort toward oligonuclear complexes, since they often interconvert between stable and adaptable conformers that respond to the changes in the surroundings (Bodenthin et al., 2009; Halder, 2002; and Wang et al., 2013). For example, homometallic, heterometallic, and mixed valence $[2 \times 2]$ grid complexes, which are actively pursued for high-density data storage and miniaturization in the field of molecular electronics, have recently emerged as self-assembling nanosized platforms that can sustain multiple spin-switching (Schäfer et al., 2016; Matsumoto et al., 2014; Schneider et al., 2013; Schneider et al., 2010; Wu et al., 2009; and Nihei et al., 2005), charge transfer (Ohkoshi et al., 2011; Liu et al., 2010; and Zhang et al., 2010), and redox modulation (Shen et al., 2015; Wang et al., 2013; Schneider et al., 2010; Ruben et al., 2004; and Uppadine et al., 2004). The optimization of these properties could ultimately produce photosensitizers, reactive centers, or catalysts achieving superior operando performances. However, unlike for the single-crystal and film morphologies, functionalities based on manipulating the spin degrees of freedom with visible photons have not been demonstrated to date for solvated metallogrid complexes (Kumar and Ruben, 2017). This status can be ascribed to the fact that their basic photophysical properties have rarely been investigated in the solution phase. A fundamental difficulty lies in tracing the detailed map of the competing deactivation pathways that are mediated by intersystem crossing (ISC), internal conversion (IC), internal vibrational relaxation (IVR), and vibrational cooling (VC) to the solvent. Consequently, establishing clear correlations between the nuclearity of the large molecular assembly, the connectivity of the multi-site ligand scaffold, and the intrinsic rate of the PSS process requires combining the quantitative results of several ultrafast spectroscopic measurements. From the accumulated experience about the PSS in solvated mononuclear $\mathrm{Fe}^{\mathrm{II}}$ complexes, transient optical absorption (TOA) spectroscopy in the UV-visible range can monitor the population of the bright states reached through dipole-allowed transitions, such as the metal-toligand-charge-transfer (MLCT) state, which subsequently leads to the formation of the lowest-lying quintet HS state. The technique also delivers the lifetime of the metastable state through the kinetics of the ground-state bleach recovery (i.e., HS $\rightarrow$ LS transition). In few cases, transient infrared absorption (TIA) spectroscopy (Wolf et al., 2008; Zerdane et al., 2018a; Collet et al., 2019) and transient Raman spectroscopy (Smeigh et al., 2008 and Collet et al., 2019) have been used to follow the vibrational relaxation toward the dark thermalized HS state in related mononuclear $\mathrm{Fe}^{\mathrm{II}}$ complexes. Utilizing the high photon energies delivered by the X-ray Free Electron Laser (XFEL) facilities, transient $\mathrm{x}$-ray emission (TXE) spectroscopies of the $\mathrm{Fe}^{\mathrm{II}} \mathrm{Ka}$ lines $\left(2 \mathrm{p}_{3 / 2,1 / 2} \rightarrow 1 \mathrm{~s}\right)$ and $\mathrm{Fe}^{\mathrm{II}} \mathrm{K} \beta$ lines $\left(3 \mathrm{p}_{3 / 2,1 / 2} \rightarrow 1 \mathrm{~s}\right)$ have been employed to uncover the spin multiplicity of the optically dark metal-centered (MC) states involved in the formation of the HS state (Zhang et al., 2014; Zhang and Gaffney, 2015) and, more generally, to map out the photoinduced spin-dynamics in homoleptic and heteroleptic mononuclear $\mathrm{Fe}^{\mathrm{II}}$ complexes (Zhang et al., 2017; Kjær et al., 2018; 2019; and Kunnus et al., 2020). The present work reports the first steps toward obtaining exhaustive characterizations of the photoinduced dynamics in oligonuclear TM complexes using mid-IR, UV-vis, and x-ray femtosecond pulses. The reversible photocycle of a solvated pyrazolatebridged $[2 \times 2] \mathrm{Fe}^{\mathrm{II}}$ metallogrid complex is probed with femtosecond TOA and TIA spectroscopies along with TXE spectroscopy at the FXE instrument (Galler et al., 2019; Khakhulin et al., 2020) of the European XFEL (EuXFEL) facility (Altarelli, 2015; Tschentscher et al., 2017). Correlating the relevant time scales associated with the coupled electronic, vibrational, and spin dynamics allows building a detailed picture of the PSS process in this important family of oligonuclear TM complexes that will guide the development of their light-driven applications based on spin-switching in the solution phase.

\section{RESULTS}

The $[2 \times 2]$ metallogrid complex $\left[\mathrm{Fe}_{4}(\mathrm{~L})_{4}\right]\left(\mathrm{BF}_{4}\right)_{4}$ (noted $\mathrm{Fe} 4)$ is formed around the pyrazole-based compartmental ligand bis $\left(2,2^{\prime}\right.$-bipyridine)-6,6' - (3,5-pyrazol) [noted HL, see Fig. 1(a)] (van der Vlugt et al., 2008). The coordination sphere of each $\mathrm{Fe}^{\mathrm{II}}$ 


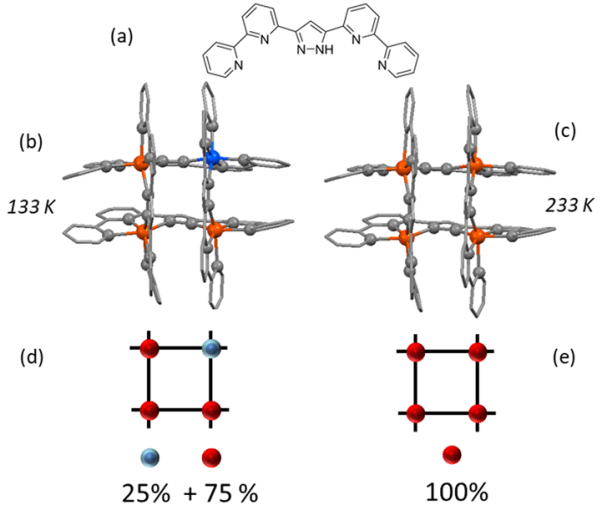

FIG. 1. (a) Compartmental ligand HL. Crystallographic structures at (b) $133 \mathrm{~K}$ and (c) $233 \mathrm{~K}$ reported by Schneider et al. (2010), with schematic illustration of their respective molecular structures with spin composition [(d) and (e)]. The LS and HS centers are displayed in blue and red, respectively.

center consists of two quasi-orthogonal terpyridine-like binding units, each belonging to two compartmental deprotonated ligands L. The molecular structure of $\mathrm{Fe} 4$ with the $\mathrm{BF}_{4}{ }^{-}$counter-anion determined through $\mathrm{x}$-ray crystallography depends on the temperature (Schneider et al., 2010). At $133 \mathrm{~K}$, a single $\mathrm{Fe}^{\mathrm{II}}$ center is in the $\left(\mathrm{t}_{2 \mathrm{~g}}\right)^{6}$ LS configuration, while three $\mathrm{Fe}^{\mathrm{II}}$ centers are in the $\left(\mathrm{t}_{2 \mathrm{~g}}\right)^{4}\left(\mathrm{e}_{\mathrm{g}}\right)^{2} \mathrm{HS}$ configurations [Fig. 1(b)]. The average metal-ligand bond lengths, $\mathrm{R}_{\mathrm{av}}$, are $1.99 \AA$ for the LS center and $2.17 \AA, 2.18 \AA$, and $2.19 \AA$ for the 3 HS centers. At $233 \mathrm{~K}$, the Fe ${ }^{\mathrm{II}}$ center in the LS state undergoes a thermal transition to the HS state [Fig. 1(c)]. The $\mathrm{R}_{\mathrm{av}}$ are then 2.16 $\AA$ for the switching center and $2.18 \AA$ for the other 3 HS centers. The LS $\rightarrow$ HS transition at room temperature is also accompanied by a greater degree of angular distortion (Schneider et al., 2010). Figures $1(\mathrm{~d})$ and $1(\mathrm{e})$ provide the simplified sketches of the molecular structures that will be employed to illustrate the changes in spin speciation upon solvation and photoexcitation.

Figure 2(a) shows the Mössbauer measurements on $\mathrm{Fe} 4$ in frozen in $\mathrm{MeCN}$ at $80 \mathrm{~K}$, which indicates a spin-state ratio LS:HS of 52:48. For the magnetic characterization, dimethylformamide (DMF) was chosen as a solvent since the solubility of $\mathrm{Fe} 4$ in $\mathrm{MeCN}$ is not sufficiently high to allow meaningful superconducting quantum interference device (SQUID) magnetometry. Figure 2(b) displays the magnetic measurements for the Fe4 complex dissolved in DMF as a function of temperature from $2 \mathrm{~K}$ to $350 \mathrm{~K}$. Over the range $40-200 \mathrm{~K}$, the [2LS-2HS] species is exclusively present in solution. As the temperature rises, the population of HS centers increases. Using $\chi_{M} T$ $([1 \mathrm{LS}-3 \mathrm{HS}])=9.3 \mathrm{~cm}^{3} \mathrm{~mol}^{-1} \mathrm{~K}$ (i.e., $100 \%$ of [1LS-3HS]) and $\chi_{M} \mathrm{~T}$ $([2 \mathrm{LS}-2 \mathrm{HS}])=6.2 \mathrm{~cm}^{3} \mathrm{~mol}^{-1} \mathrm{~K}$ (i.e., $0 \%$ of [1LS-3HS]), the experimental value $\chi_{M} \mathrm{~T}$ of $8.09 \mathrm{~cm}^{3} \mathrm{~mol}^{-1} \mathrm{~K}$ obtained at $295 \mathrm{~K}$ gives $39: 61$ for the ratio [2LS-2HS]:[1LS-3HS], which translates into an overall LS:HS ratio of $35: 65 \% \pm 5 \%$.

$\mathrm{X}$-ray emission spectroscopy (XES) measurements of the $\mathrm{Ka}_{1,2}$ and $\mathrm{K} \beta$ lines were then conducted in order to establish the spin speciation in $\mathrm{MeCN}$ at room temperature. When the orbital angular momentum of the valence shell is equal to zero and when relativistic interactions can be neglected, the multiplet theory predicts a linear
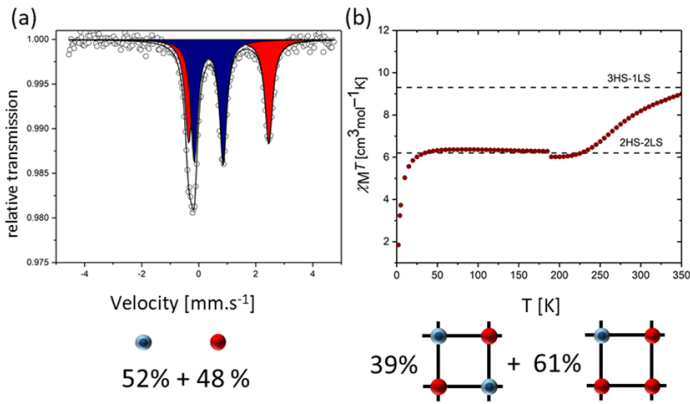

FIG. 2. (a) Zero-field ${ }^{57} \mathrm{Fe}$ Mössbauer spectrum of Fe4 in frozen MeCN at 80 $\mathrm{K}$. The lines represent simulations with Lorentzian doublets for HS-Fe"l (red; $\delta=1.05 \mathrm{~mm} \mathrm{~s}^{-1}, \Delta \mathrm{E}_{\mathrm{Q}}=2.81 \mathrm{~mm} \mathrm{~s}^{-1}$, and rel. intensity: $48 \%$ ) and LS-Fell (blue; $\delta=0.35 \mathrm{~mm} \mathrm{~s}^{-1}, \Delta \mathrm{E}_{\mathrm{Q}}=1.01 \mathrm{~mm} \mathrm{~s}^{-1}$, and rel. intensity: $52 \%$ ). (b) Magnetic susceptibility measurement of $\mathrm{Fe} 4$ in DMF from 2 to $350 \mathrm{~K}$. The dotted lines represent the expected values for the [1LS-3HS] and [2LS-2HS] states. The LS and HS centers are displayed in blue and red, respectively.

relationship between the $(2 p, 3 d)$ exchange energy splitting and the number of unpaired electrons (Glatzel). As a result, the width of the $\left(2 \mathrm{p}_{3 / 2} \rightarrow 1 \mathrm{~s}\right) \mathrm{Ka}_{1}$ line reflects the spin at the $3 \mathrm{~d}$ metal center. Figure 3(a) shows the $\mathrm{Ka}_{1,2}\left(2 \mathrm{p}_{3 / 2,1 / 2} \rightarrow 1 \mathrm{~s}\right)$ lines for $\mathrm{Fe} 4$ in $\mathrm{MeCN}$ after normalization by the total area. The asymmetry in the $\mathrm{Ka}_{1}$ line shape is related to the significant fraction of the HS state in the solvated sample. Figure $3(\mathrm{~b})$ shows the $\mathrm{K} \beta\left(3 \mathrm{p}_{3 / 2,1 / 2} \rightarrow 1 \mathrm{~s}\right)$ lines for the Fe4 metallogrid complex in $\mathrm{MeCN}$ after normalization by the area. The accurate determination of the spin-state from these lines is achieved through monitoring the satellite feature at $7045 \mathrm{eV}$. Spectral decomposition as a linear combination fit (LCF) based on the solvated mononuclear LS and HS references $\left[\mathrm{Fe}^{\mathrm{II}}(\mathrm{bpy})_{3}\right]\left(\mathrm{PF}_{6}\right)_{2}$ (where bpy $=2,2^{\prime}$-bipyridine) in $\mathrm{MeCN}$ and $\left[\mathrm{Fe}^{\mathrm{II}}\left(\mathrm{H}_{2} \mathrm{O}\right)_{6}\right]\left(\mathrm{BF}_{4}\right)_{2}$ in $\mathrm{H}_{2} \mathrm{O}$ yields $37 \% \pm 3 \%$ of LS and $63 \% \pm 3 \%$ of $\mathrm{HS}$ for $\mathrm{Fe} 4$ in $\mathrm{MeCN}$. The spin state composition is illustrated with the sketch in Fig. 3(c). The K $\beta$ profiles for the mononuclear reference complexes are reported in Sec. S.I.1. The comparison between the spin distributions in the solution, powder, and single-crystalline phases summarized in Table S.I.2 shows that the Fe4 metallogrid complex is strongly affected by the environment.
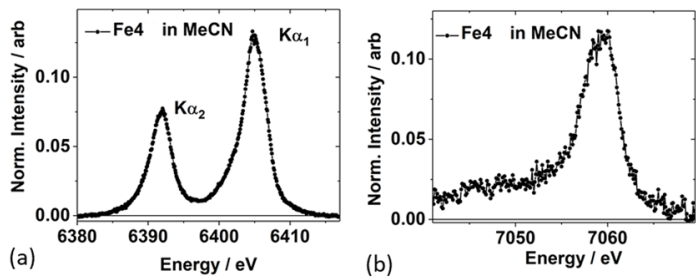

(c)

$37 \%+63 \%$

FIG. 3. (a) $\mathrm{Ka}_{1,2}$ lines, (b) $\mathrm{K} \beta$ lines, and (c) spin composition for Fe4 solvated in $\mathrm{MeCN}$ at room temperature. The LS and HS centers are displayed in blue and red, respectively. 
The UV-visible absorption spectrum of $\mathrm{Fe} 4$ in $\mathrm{MeCN}$ at room temperature is displayed in Fig. 4. The line shape is consistent with the one reported in the literature (Schneider et al., 2010). The oscillator strength below $350 \mathrm{~nm}$ is attributed to overlapping ligandbased transitions, while the broad band spanning the $450-700 \mathrm{~nm}$ range is assigned to a metal-to-ligand-charge-transfer (MLCT) transition of mixed singlet-triplet character. The values of the extinction coefficient are given in Sec. S.I.3 for the selected wavelengths. Assuming that the individual $\mathrm{Fe}^{\mathrm{II}}$ centers are only weakly electronically coupled, they should retain their isolated properties once they are linked. Therefore, the absorbance of the [2LS-2HS] species should be around twice that of the [1LS-3HS] species in the visible range. Temperature-dependent measurements show that the oscillator strength is due to the LS units and that a thermalized HS state does not contribute to the absorbance in this spectral region (see Sec. S.I.4).

Figure 5(a) presents the photoinduced dynamics following the femtosecond laser excitation of $\mathrm{Fe} 4 \mathrm{in} \mathrm{MeCN}$ at $385 \mathrm{~nm}$ at room temperature for a fluence of about $0.3-1.1 \mathrm{~mJ} / \mathrm{cm}^{2}$. The setup is described in Sec. S.I.5. The singular value decomposition (SVD) analysis based on a simple sequential model identifies three clear components with distinct time constants (Sec. S.I.6). The decay associated spectra (DAS) are displayed in Fig. 5(b). The first component (red line) is formed instantaneously with a time constant $\tau_{1}$ of about $200 \mathrm{fs}$, which is instrument-limited. It comprises a bleach signal (B1) and a broad excited state absorption (ESA) signal that cover the blue $\left(A_{1}\right)$ and red $\left(A_{1}{ }^{\prime}\right)$ regions of $D_{A S}$. The second component (blue line) that corresponds to the time constant $\tau_{2}$ of 15 ps reflects the growth of the bleach $\left(\mathrm{B}_{2}\right)$ and a weaker ESA in the blue $\left(\mathrm{A}_{2}\right)$ and red $\left(\mathrm{A}_{2}{ }^{\prime}\right)$ regions of $\mathrm{DAS}_{2}$. The third component matches the negative of the absorption spectrum $\left(B_{3}\right)$, which is shown as the gray trace in Fig. 5(b). It decays over a time scale exceeding the temporal window covered by the transient absorption setup employed for this measurement. Figure 5(c) shows the optical kinetics that track the temporal evolution of the ground state bleach at $460 \mathrm{~nm}$ and the excited manifold at $360 \mathrm{~nm}$. The high-frequency oscillations in the first few picoseconds are presented in the inset. It should be noted that the oscillatory behavior is not observed in the $460 \mathrm{~nm}$ kinetics so that there is no impulsive excitation on the PES of the LS (Cannizzo et al., 2010). Fitting a double-exponential to the kinetics trace at $360 \mathrm{~nm}$ and subtracting it in order to extract the residual oscillations deliver a period of $600 \pm 20 \mathrm{fs}$ (Sec. S.I.7). The schematic in Fig. 5(d) illustrates the global PSS in Fe4 solvated

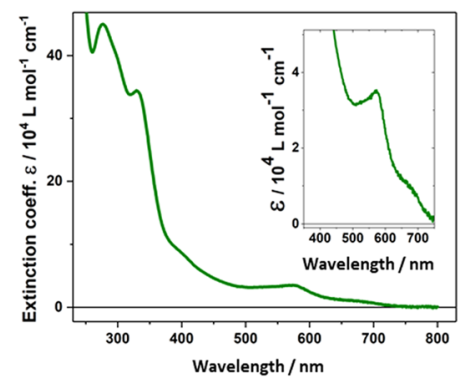

FIG. 4. Extinction coefficient of $\mathrm{Fe} 4$ in $\mathrm{MeCN}$ over the UV-visible spectral range.

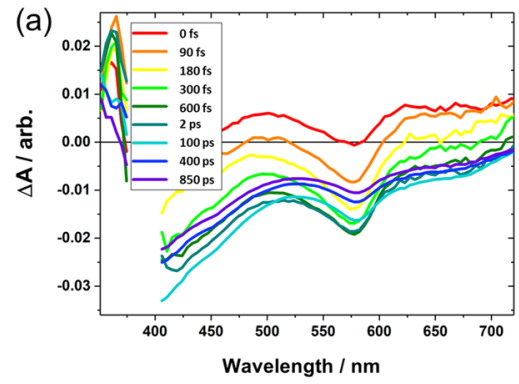

(b)

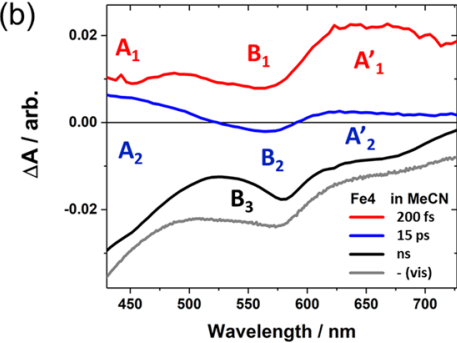

(c)

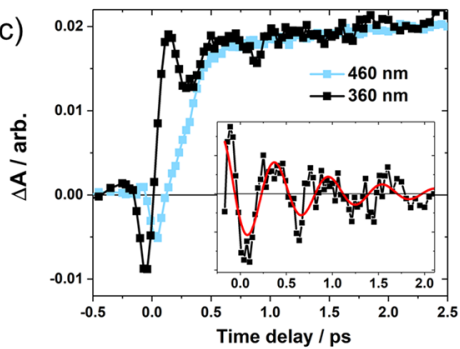

(d)
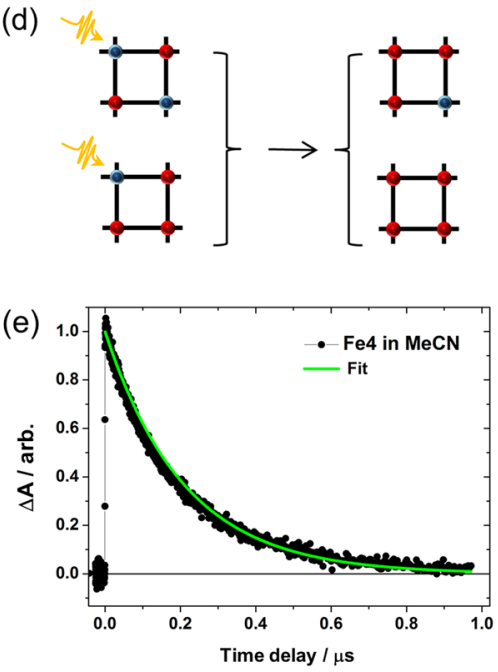

FIG. 5. (a) Transient optical spectra following excitation at $385 \mathrm{~nm}$ of $\mathrm{Fe} 4$ in $\mathrm{MeCN}$ at different time delays. (b) Decay associated spectra from the SVD with the inverted UV-visible spectrum (gray, scaled and offset for visual comparison). (c) Kinetic at $360 \mathrm{~nm}$ (black) and $460 \mathrm{~nm}$ (blue). The inset shows the oscillations extracted from the kinetics at $360 \mathrm{~nm}$ fitted with a damped sine curve (red). (d) Schematic of the PSS for Fe4 solvated in MeCN. The LS and HS centers are displayed in blue and red, respectively. (e) Nanosecond kinetics acquired with laser excitation at $400 \mathrm{~nm}$ (black dots) and single exponential fit (green line). 
in $\mathrm{MeCN}$. The nanosecond kinetics following excitation at $400 \mathrm{~nm}$ are shown in Fig. 5(e). The single-exponential lifetime is fitted to $210 \pm 5 \mathrm{~ns}$. As determined with SQUID and steady-state XES measurements, the Fe4 metallogrid complex solvated in $\mathrm{MeCN}$ is a mixture of two molecular species, namely, [2LS-2HS] and [1LS-3HS] species at room temperature. The analysis of the transient optical absorption measurements in the UV-visible indicates that a single photoexcited intermediate state leads to the formation of a longliving metastable state. This transient species is characterized by its well-defined single-exponential behavior with a time constant of 15 ps. However, its exact nature cannot be established based on the TOA measurements alone because its spectral line shape is broad and featureless.

TXE measurements with femtosecond resolution were then performed in order to assign unambiguously the spin multiplicity of the intermediate excited states. The experimental setup and the data extraction procedures are described in Sec. S.I.8. Figures 6(a) and 6 (b) show the transient $\mathrm{Ka}_{1,2}$ and $\mathrm{K} \beta$ signals (black dot traces), respectively, at a time delay $\Delta \mathrm{t}=2$ ps following $400 \mathrm{~nm}$ excitation with a fluence of $55 \mathrm{~mJ} / \mathrm{cm}^{2}$ (after 3-point rebinning). Comparing with signals built from the mononuclear reference traces shows that the intermediate and metastable excited-states belong to the quintet manifold. Direct scaling to these reference signals (green line traces) delivers comparable excited state fractions of $17 \% \pm 5 \%$ and $20 \%$ $\pm 8 \%$ from the $\mathrm{Ka}_{1}$ and the $\mathrm{K} \beta$ measurements, respectively. The power dependency of the $\mathrm{K} \alpha_{1}$ upon the incident fluence is given in Sec. S.I.9.

Figure 7 shows the $\mathrm{Ka}_{1}$ kinetics acquired within 6400.2-6409.4 $\mathrm{eV}$ (see Sec. S.I.8). Fitting the rise by a Gaussian-broadened Heaviside function suggests a $\sigma=140 \pm 70 \mathrm{fs}$, hence a full-width at half maximum (FWHM) of $330 \pm 165$ fs for the instrument response function (IRF), in agreement with published reports at the time of these XFEL experiments (Kirkwood et al., 2019) (see Sec. S.I.10). In other words, the quintet character is acquired on the sub-picosecond time scale.

Further information about the relaxation dynamics from the initial Franck-Condon state is obtained with TIA spectroscopy. The first study on the sub-picosecond time scale was performed on the two related mononuclear $\mathrm{Fe}^{\mathrm{II}}$ complexes $[\mathrm{Fe}(\mathrm{btpa})]^{2+}$ and $[\mathrm{Fe}(\mathrm{b}(\mathrm{bdpa}))]^{2+}$ (where btpa $=\mathrm{N}, \mathrm{N}, \mathrm{N}^{\prime}$, $\mathrm{N}^{\prime}$-tetrakis(2-pyridylmethyl)-6,6'-bis(aminomethyl)-2,2' -bipyridine (a)

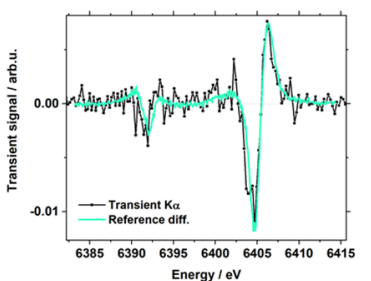

(b)

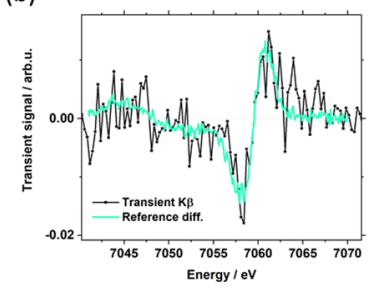

FIG. 6. (a) Transient $\mathrm{Ka}_{1}$ and $\mathrm{Ka} \alpha_{2}$ and (b) transient $\mathrm{K} \beta$ signals at $\Delta t=2 \mathrm{ps}$ for Fe4 dissolved in MeCN following $400 \mathrm{~nm}$ excitation (black dots). Scaling the reference traces (green lines) constructed from mononuclear LS and HS complexes delivers comparable excited state fractions of $17 \% \pm 5 \%$ ( $\mathrm{Ka}_{1}$ measurements) and $20 \% \pm$ $8 \%$ (K $\beta$ measurements).

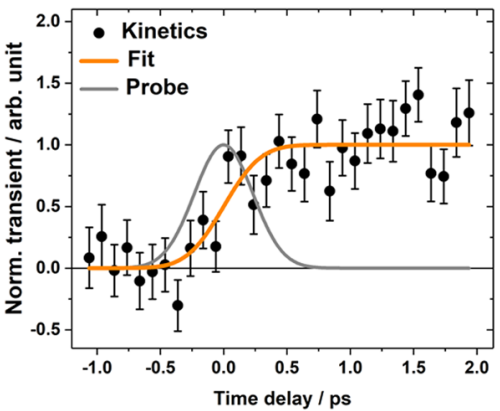

FIG. 7. Ka kinetics (black dots) with single-exponential fit (orange line) and the corresponding IRF (gray line).

and $\mathrm{b}($ bdpa $)=\mathrm{N}, \mathrm{N}^{\prime}$-bis(benzyl)-N, $\mathrm{N}^{\prime}$-bis(2-pyridylmethyl-6,6 $6^{\prime}$-bis (aminoethyl))-2,2' -bipyridine) possessing similar multidentate coordination spheres (Wolf et al., 2008). For these systems, the most pronounced differences were observed in the spectral range of 1000$1065 \mathrm{~cm}^{-1}$. Comparison with density functional theory (DFT) calculations showed that the modes responsible for the transient signals in these systems have significant metal-ligand stretching character. Figure 8(a) shows the steady-state spectrum of $\mathrm{Fe} 4$ in $\mathrm{MeCN}-\mathrm{d} 3$ and its evolution following photoexcitation at $385 \mathrm{~nm}$ in the 1400 $1650 \mathrm{~cm}^{-1}$ spectral range for a power of $0.4 \mathrm{~mW}$. The steady-state spectrum resembles that of the closely related mononuclear complex $\left[\mathrm{Fe}(\text { terpy })_{2}\right]^{2+}$ (see Sec. S.I.11). The transient signal is characterized by the quasi-instantaneous appearance of differential bands within the response function of the instrument. The spectral evolution is on the tens of ps time scale before reaching a line shape that remains constant over the covered temporal window. As for the UV visible data, SVD analysis can be performed with a sequential model and two single-exponential decays [Fig. 8(b)]. The first component appears within the response function of the instrument of $200 \mathrm{fs}$ and displays a time constant of 14 ps. This matches the values obtained for the intermediate species monitored in the UV-vis region.

For a molecular assembly as large as the Fe4 metallogrid complex, calculating the IR frequencies was beyond the computational resources that could be accessed at the time of this study. However, useful insight can be obtained from simple considerations. The first component (green trace) matches very well the derivative (gray trace) of the GS spectrum (black trace), which is the signature of a global shift for all the frequencies to lower wavenumbers (i.e., to lower energies). This can be ascribed to a weakening of the elongated metal-ligand bonds, resulting in lower force constants. For the long-lived nanosecond component (purple trace), some of the initial frequencies gain intensities (features $\mathrm{A}, \mathrm{B}, \mathrm{C}$, and D in the purple trace) while narrowing (features $A$ and $B$ in the purple trace). This finding follows the general trend observed in the photoexcited $\mathrm{Fe}^{\mathrm{II}}$ mononuclear complexes, where the absorption cross section in the infrared (IR) is enhanced upon LS $\rightarrow$ HS transition (Wolf et al., 2008; Lawson Daku and Hauser, 2010; Lawson Daku, 2018; and Lawson Daku, 2019), associated with increased entropy. 

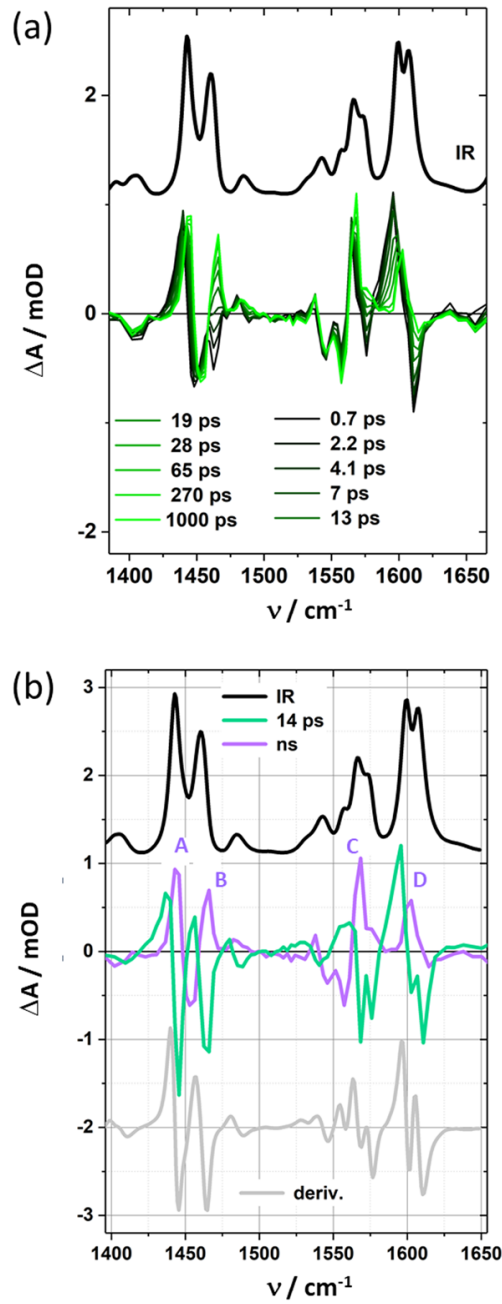

FIG. 8. (a) Spectral evolution of the transient signal in the IR region for different time delays. (b) Decay associated spectra from the SVD analysis (green and purple lines), compared to the steady state spectrum (black line) and its derivative (gray line).

\section{DISCUSSIONS}

The analysis of kinetics obtained from TOA, TXE, and TIA delivers several time scales that should be correlated in order to yield a detailed description of the PSS process within the Fe4 metallogrid complexes solvated in $\mathrm{MeCN}$. The ultrafast optical kinetics in the UV-visible and IR range indicate that a well-defined photoexcited species, characterized by its specific single-exponential behavior, evolves with a time constant of tens of ps toward a metastable state that lives for hundreds of ns. The ultrafast $\mathrm{Ka}_{1} \mathrm{X}$-ray kinetics show that this intermediate state possesses a quintet character. Photoexcitation of the solvated Fe4 does not appreciably change the vibrational spectrum in the IR region but induces a sub-ps weakening of all the force constants attributed to the population of the antibonding orbitals of $e_{g}$ character in the HS manifold. The vibra- tional coherence observed during the single-exponential decay is particularly notable considering the fact that the initial sample is a mixture of two large molecular species. These findings suggest that the $\mathrm{Fe}^{\mathrm{II}}$ LS centers in the two types of metallogrids can be independently photoexcited to HS states, as anticipated from an assembly that is weakly electronically coupled. DFT calculations using BLYP$\mathrm{d} 3$ in the gas phase and with a COSMO model for solvation were performed in order to establish the structures and energetics of the [4LS-0HS], [3LS-1HS], [2LS-2HS], [1LS-3HS], and [0LS-4HS] species. The average metal-ligand bond lengths, $\mathrm{R}_{\mathrm{av}}$, for the four centers in each species are summarized in Sec. S.I.12. The gas phase structures are in good agreement with the ones obtained in previous computational studies conducted with a similar methodology (Zueva et al., 2011; Borshch and Zueva, 2012). The calculated $\mathrm{R}_{\mathrm{av}}$ of the [1LS-3HS] and [0LS-4HS] species reproduce the tendency reported upon thermal switching in the crystallographic structures measured at $133 \mathrm{~K}$ and $233 \mathrm{~K}$, considering the expected solid-state effects, e.g., packing forces. The energy diagram for the solvated species is displayed in Fig. 9, with $\left[\mathrm{Fe}(\text { terpy })_{2}\right]^{2+}$ in $\mathrm{MeCN}$ for comparison (see Sec. S.I.12). The values of the energy gaps are given in Sec. S.I.12.

It should be noted here that state-of-the-art DFT methods are still generally failing to provide accurate predictions of the HS-LS energy difference, even for mononuclear transition metal complexes. In this work, the choice of BLYP-d3 was motivated by the fact that it belongs to the family of the so-called GGA functionals. This made it possible to carry out the efficient computational study of the large

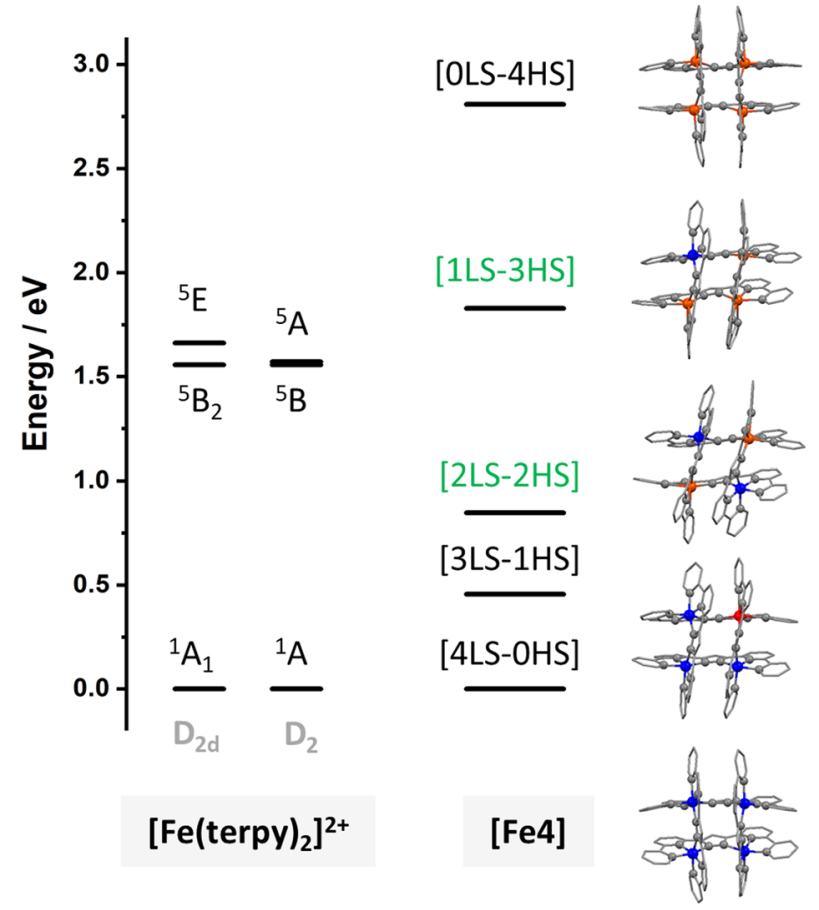

FIG. 9. Energy diagram for $\mathrm{Fe} 4$ in $\mathrm{MeCN}$ compared with the mononuclear $\left[\mathrm{Fe}(\text { terpy })_{2}\right]^{2+}$ in MeCN for $\mathrm{D}_{2 \mathrm{~d}}$ and $\mathrm{D}_{2}$ symmetries. The LS and HS centers are displayed in blue and red, respectively. The calculations were performed with the BLYP-d3 functional. 
Fe4 grid targeted in this work. It is well-known that GGA functionals tend to overestimate the stability of the LS state with respect to the HS state in mononuclear Fe(II) complexes (Lawson Daku et al., 2012). In addition, a purely electronic calculation does not account for the crucial vibrational and entropic contributions. For both reasons, the absolute energy differences obtained through the present DFT optimizations are not expected to be strictly comparable to the ones of relevance in the experiment, including $\mathrm{kT}$ at room temperature. However, intensive benchmarking has established that the relative energy spacings in closely related complexes are accurately captured by DFT calculations (e.g., Lawson Daku, 2019; 2005; Vargas et al., 2013; Phan et al., 2017; Bowman and Jakubikova, 2012; and Petzold et al., 2017). This argument can be used to explain certain trends in physicochemical observables, e.g., here the lifetime of the photoexcited [1LS-3HS] and [0LS-4HS] in Fe4 and of the $\mathrm{HS}$ in $\left[\mathrm{Fe}(\text { terpy })_{2}\right]^{2+}$. The rates of $\mathrm{HS} \rightarrow \mathrm{LS}$ transitions vary in accordance with the inverse energy gap law, which is holding in the solution phase (Hauser et al., 1991; Hauser, 1995; 2004; and Liu et al., 2017). Since $\Delta \mathrm{E}_{0}([1 \mathrm{LS}-3 \mathrm{HS}]-[2 \mathrm{LS}-2 \mathrm{HS}])=0.9812 \mathrm{eV}$ and $\Delta \mathrm{E}_{0}([0 \mathrm{LS}-4 \mathrm{HS}]-[1 \mathrm{LS}-3 \mathrm{HS}])=0.9807 \mathrm{eV}$, the decay kinetics of the metastable HS states back to their respective ground state [1LS-3HS] $\rightarrow[2 \mathrm{LS}-2 \mathrm{HS}]$ and $[0 \mathrm{LS}-4 \mathrm{HS}] \rightarrow[1 \mathrm{LS}-3 \mathrm{HS}]$ are expected to be very similar.

Overall, the photoinduced dynamics do not exhibit any detectable dependency upon the spin composition of a given metallogrid. Therefore, they can be described in terms of intra-site transitions. Upon photoexcitation, a vibrational wavepacket is created in the quintet manifold on the few hundreds of fs by the coherent excitation of modes that are similar to the ones in the LS state, but downshifted in energy. The vibrationally hot HS state thermalizes within tens of ps to a long-living HS state. This time scale is typical for the equilibration of the photoinduced HS state in mononuclear $\mathrm{Fe}^{\mathrm{II}}$ complexes with a flexible coordination sphere (Wolf et al., 2008). The reversible photocycle is summarized in Fig. 10.

The photoinduced dynamics in Fe4 can be compared to the ones reported for the closely related mononuclear complex $\left[\mathrm{Fe}(\text { terpy })_{2}\right]^{2+}$ that also imposes a tridentate coordination sphere for the $\mathrm{Fe}^{\mathrm{II}}$ center. In this complex, photoabsorption in the visible range creates a coherent superposition of excited vibrational modes (i.e., a nuclear wavepacket) in the quintet manifold. The vibrationally hot HS thermalizes and decays back to the LS ground state within a few nanoseconds in MeCN and water (Liu et al., 2017; Canton et al.,

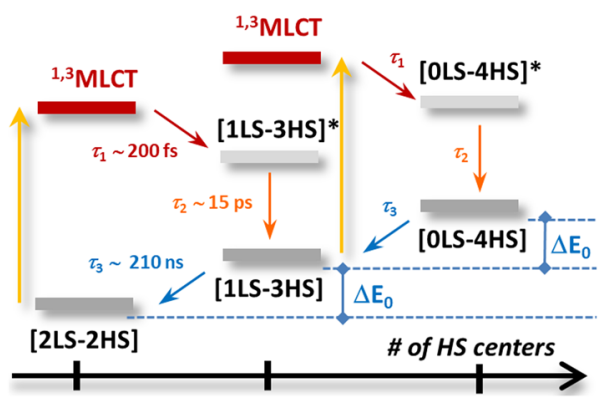

FIG. 10. Schematic photocycle for $\mathrm{Fe} 4$ in $\mathrm{MeCN}$.
2014; Zhang et al., 2015; and Vankó et al., 2015). The prolonged lifetimes are in line with the larger energy gap $\Delta \mathrm{E}_{0}([\mathrm{HS}]-[\mathrm{LS}])$ calculated for the LS and HS state of $\left[\mathrm{Fe}(\text { terpy })_{2}\right]^{2+}$ in $\mathrm{D}_{2 \mathrm{~d}}$ and $\mathrm{D}_{2}$ symmetries (see Fig. 9).

Besides energetic factors, further modulation of the HS $\rightarrow$ LS transition rate in $\left[\mathrm{Fe}(\text { terpy })_{2}\right]^{2+}$ arises due to the deviation of the reaction coordinate from an isotropic single configuration coordinate. For this complex, the reaction coordinate cannot be approximated by a simple average $\mathrm{Fe}-\mathrm{N}$ bond elongation, e.g., it is anisotropic (Nance et al., 2015; Canton et al., 2014; 2015; and Zhang et al., 2015). As revealed by powerful studies combining ligand design, crystallography, and modeling tools, such anisotropy is the key to stabilizing the HS state (Steinert et al., 2016; Stock et al., 2016; 2012; 2017a; 2017b; Phan et al., 2017; and Kroll et al., 2019). A significant increase in the HS lifetime of mononuclear complexes occurs when radial and angular motions are coupled during the rearrangement of the ligand scaffold (Marchivie et al., 2005; Buhks et al., 1980; Hauser et al., 1991; 1995; 2004; and Gütlich et al., 1994), e.g., through a trigonal prismatic deformation known as the Bailar twist (Bailar, 1958), which was already proposed in the 1980s (Rodger and Johnson, 1988; Vanquickenborne and Pierloot, 1981; McCusker et al., 1992; and McCusker et al., 1993). The present work illustrates how linking several metal centers into oligonuclear complexes can be developed as an efficient synthetic strategy to increase the lifetime of the photoinduced metastable spin-state, hence preventing thermal spin-scrambling. Comparing the lifetime observed for photoexcited Fe4 ( 210 ns) with the one reported for photoexcited Fe3 ( $123 \mathrm{~ns}$ ) (Naumova et al., 2020) pinpoints the global nuclearity of the architecture as a tailoring parameter. Eventually, the balance between the connectivity and the rigidity of the molecular assembly can be further tuned toward promoting vibrational coherence while influencing the overall kinetics.

Finally, Fig. 10 suggests that the metallogrid architecture will be well-suited for creating non-Boltzmann distributions of spin multiplicities. In the particular case of $\mathrm{Fe} 4$, the decay [1LS-3HS] $\rightarrow$ [2LS-2HS] and [0LS-4HS] $\rightarrow$ [1LS-3HS] takes place on very similar time scales. However, for example, if [0LS-4HS] $\rightarrow$ [1LS$3 \mathrm{HS}$ ] could be accelerated (e.g., in a heteroleptic oligonuclear assembly), the photoinduced population of the [1LS-3HS] species would be strongly out of equilibrium on the ns to $\mu$ s time scale, thereby imparting unusual transient properties to the mixture of species.

The present study highlights the fact that tapping into the reactivity of the hot spin-states produced by PSS in metallogrid complexes is well within reach. However, several open questions have to be answered before mechanistic models can be built to guide their systematic integration into new photoconversion schemes. Synergetic methodologies based on synthetic chemistry, ultrafast spectroscopies, and theoretical modeling should be devised in order to refine the current understanding of the PSS process as a function of fluence (Bertoni et al., 2015; Zerdane et al., 2018a), excitation wavelength (Zerdane et al., 2018a; 2019), and solvent (Zerdane et al., 2018b). The impact of the local coordination geometry on the lifetime of the HS state has been reported in mononuclear complexes, e.g., bidentate in $\left[\mathrm{Fe}(\mathrm{bpy})_{3}\right]^{2+}$ (Gawelda et al., 2007; Cannizzo et al., 2010; Auböck and Chergui, 2015; Chergui and Collet, 2017; and Lawson Daku, 2018) vs tridentate in $\left[\mathrm{Fe}(\text { terpy })_{2}\right]^{2+}$ (Canton et al., 2014; Zhang et al., 2015; 
Bowman and Jakubikova, 2012; Petzold et al., 2017; and Lawson Daku, 2019). Improving the monodispersity of the oligonuclear samples in their ground state would clarify all the spectroscopic measurements since the mixtures of species complicate their analysis. Architectures where the number of connected units can be systematically incremented from the mononuclear building block to the complete metallogrid complex would be particularly valuable for studies aiming at determining accurate absorption cross sections and unraveling the impact of multiple excitation events. Capabilities for large-scale calculations of vibrational manifolds should be implemented for assigning the IR-active marker bands to vibrational modes of the complex undergoing PSS. Transient XES measurements with higher temporal resolution and higher signal to noise ratios will clarify the exact nature of the intermediate manifold and the role of metal centers, as for mononuclear Fe ${ }^{\mathrm{II}}$ complexes. Finally, transient X-ray absorption spectroscopy (Bressler et al., 2009; Cammarata et al., 2014; Lemke et al., 2013; 2017; and Britz et al., 2020) and transient wide-angle $\mathrm{x}$-ray scattering displaying increased structural sensitivity with hard $\mathrm{x}$ rays (Khakhulin et al., 2019) could also be applied to capture the local and global structural dynamics on the relevant time scales and length-scales associated with the photoreactivity triggered by the PSS process in solvated metallogrid complexes.

\section{CONCLUSIONS}

In conclusion, the present work initiates multi-spectroscopic studies of the PSS in solvated [2 $\times 2]$ iron(II) metallogrid complexes. The ultrafast dynamics are characterized with femtosecond pulses in the mid-infrared, UV-visible, and x-ray spectral ranges. The reversible photocycle can be described in terms of independent intra-sites transitions. Following photoexcitation, the FranckCondon state of the mixed singlet-triplet MLCT character rapidly evolves into a vibrationally hot quintet state while exhibiting coherent behavior over 1-2 ps. The thermalization toward the equilibrated state takes around 15 ps. The metastable HS state lives for several hundreds of nanoseconds, in stark contrast with the few nanosecond lifetimes reported for the related mononuclear complex $\left[\mathrm{Fe}(\text { terpy })_{2}\right]^{2+}$. This finding evidences the crucial role of the ligand connectivity and global nuclearity in stabilizing the photoproducts of the PSS. Independently addressable, energy-rich, and long-lived metastable states are favorable for achieving selective manipulation of the transient spin-state in oligonuclear complexes at the atomic level. With the rapid progress expected from crossdisciplinary investigations, the control of PSS in oligonuclear complexes will contribute to the elaboration of photoconversion schemes that can be efficiently triggered by ultrafast spin-switching.

\section{MATERIALS AND METHODS}

\section{Synthesis}

The ligand $\mathrm{HL}$ and the complex $\left[\mathrm{Fe}_{4}(\mathrm{~L})_{4}\right]\left(\mathrm{BF}_{4}\right)_{4}$ (noted Fe4) were synthesized according to the previously reported procedures (van der Vlugt et al., 2008; Schneider et al., 2010). The crystallographic structures in the CCDC are CCDC-768536 [1(BF4)4.4 DMF (133 K)] and CCDC-768537 [1(BF4)4.4 DMF $(233 \mathrm{~K})]$
The complex bis $\left(2,2^{\prime}: 6^{\prime}, 2^{\prime \prime}\right.$-terpyridine iron(II)) dihexafluorophosphate $\left(\left[\mathrm{Fe}^{\mathrm{II}}(\text { terpy })_{2}\right]\left(\mathrm{PF}_{6}\right)_{2}\right)$ was synthesized according to a previously published method (Machan et al., 2012) and was additionally recrystallized from the water/acetone mixture $(1: 2.5 \mathrm{v} / \mathrm{v})$ and dried under vacuum before use. The synthesis of $\left[\mathrm{Fe}^{\mathrm{II}}(\mathrm{bpy})_{3}\right]\left(\mathrm{PF}_{6}\right)_{2}$ was performed according to literature procedures (Kumar et al., 2016).

\section{MAGNETIC CHARACTERIZATION}

\section{Mössbauer spectroscopy measurements}

Mössbauer spectra were recorded with a ${ }^{57} \mathrm{Co}$ source in a Rh matrix using an alternating constant acceleration Wissel Mössbauer spectrometer operated in the transmission mode and equipped with a Janis closed-cycle helium cryostat. Isomer shifts are given relative to iron metal at ambient temperature. Simulation of the experimental data was performed with the Mfit program using Lorentzian line doublets: E. Bill, Max-Planck Institute for Chemical Energy Conversion, Mülheim/Ruhr, Germany.

\section{Magnetic susceptibility measurements}

Temperature-dependent magnetic susceptibility data were measured using a Quantum-Design MPMS-XL-5 SQUID magnetometer at a magnetic field of 5000 Oe. The sample was prepared by dissolving crystalline $\mathrm{Fe} 4$ in $\mathrm{MeCN}$ and sealing the solution in an nuclear magnetic resonance (NMR)-tube. Each raw data file for the measured magnetic moment was corrected for the diamagnetic contribution of $\mathrm{MeCN}$. The molar susceptibility data were corrected for the diamagnetic contribution according to $\chi_{\mathrm{Mdia}}($ sample $)=-0.5 \mathrm{M}$ $\times 10^{-6} \mathrm{~cm}^{3} \mathrm{~mol}^{-1}$.

\section{Ultrafast optical characterization}

The ultrafast optical characterization was performed on two setups achieving femtosecond and nanosecond temporal resolution. They are described in Sec. S.I.5. The details for the data treatment and subsequent analysis are given in Secs. S.I.5-S.I.7.

\section{Femtosecond TXE experiments at the FXE instrument of EuXFEL}

The TXE measurements with femtosecond resolution were performed at the FXE instrument of the European XFEL facility in the standard optical pump-X-ray probe configuration. The incoming $\mathrm{x}$-ray energy was set to $9.3 \mathrm{keV}$. The filling pattern was the standard 40 pulses at $374 \mathrm{kHz}$ in a $110 \mu$ s train with energy $\sim 1 \mathrm{~mJ} /$ pulse. The $\mathrm{x}$-ray beam was focused down to a $20 \mu \mathrm{m}$ spot. The $\mathrm{Ka}_{1,2}$ and $\mathrm{K} \beta$ emission lines were collected by $5 \mathrm{Ge}(440)$ and $8 \mathrm{Si}(531)$ crystals, respectively, in the von Hamos geometry and focused, in turn, on a 2D CCD GreatEyes detector. The optical excitation wavelength of the PPLS I laser system was $400 \mathrm{~nm}$. The pump pattern was fixed to 40 pulses/train at $374 \mathrm{kHz}$. The pulse duration was $15 \mathrm{fs}$ fwhm, and the spot size was $30 \mu \mathrm{m}$. The pump and the probe were overlapped in time and space on a flowing liquid round jet of $100 \mu \mathrm{m}$ diameter. The jet speed was adjusted to insure a refreshed spot for each pump-probe event. The concentration of $\mathrm{Fe} 4$ was $\sim 3 \mathrm{mmol}$ in $\mathrm{MeCN}$. No sample damage 
was observed either in the laser_off XES spectra or in the UVvis absorption spectra taken before/after the $\mathrm{x}$-ray measurements. The details of the XES data processing and analysis are given in Sec. S.I.8.

\section{DFT optimizations}

The geometries of the metallogrid complex Fe4 in the different spin states have been optimized in the gas phase and in acetonitrile $(\mathrm{MeCN})$ with the ADF program package [1], using the COSMO (conductor like screening model) implicit model of solvation for $\mathrm{MeCN}$ [2] and the dispersion-corrected BLYP-d3 functional [3], combined both with the Slater-type TZP basis set of triple-zeta polarized quality from the ADF basis set database [4]. The calculations were carried out within the frozen core approximation with the cores frozen up to the 1 s level for the $\mathrm{C}$ and $\mathrm{N}$ and up to the $2 \mathrm{p}$ level for the Fe atoms. They were run restricted for the [4LS-0HS] state and unrestricted for the [3LS-1HS], [2LS$2 \mathrm{HS}$, [1LS-3HS], and [0LS-4HS] states for which the z-component (quantum number MS) of the total electronic spin (quantum number $S)$ was constrained to $M_{S}=+2(S=2), M_{S}=+4(S=4)$, $\mathrm{M}_{\mathrm{S}}=+6(\mathrm{~S}=6)$, and $\mathrm{M}_{\mathrm{S}}=+8(\mathrm{~S}=8)$, respectively. The Fe-N bond lengths and the electronic energy gaps, $\Delta \mathrm{E}_{0}$, are given in the tables of S.I.12. The complete reference list for this section is given in Sec. S.I.13.

\section{SUPPLEMENTARY MATERIAL}

See the supplementary material for (Sec. S.I.1) a linear combination fit for the $\mathrm{K} \beta$ line of $\mathrm{Fe} 4$ in $\mathrm{MeCN}$, (Sec. S.I.2) comparison of the spin-state speciation in $\mathrm{Fe} 4$ solvated in $\mathrm{MeCN}$ with magnetic and spectroscopic techniques, (Sec. S.I.3) extinction coefficient at the selected wavelengths, (Sec. S.I.4) temperature dependent measurements of the UV-visible spectrum, (Sec. S.I.5) ultrafast optical characterization of photoexcited $\mathrm{Fe} 4$ in $\mathrm{MeCN}$, (Sec. S.I.6) SVD analysis of the transient optical and infrared spectra, (Sec. S.I.7) fitting of the oscillations in the transient optical absorption signal, (Sec. S.I.8) acquisition and extraction of steady-state and timeresolved $\mathrm{Ka}$ and $\mathrm{K} \beta$ XES at the FXE instrument of the European XFEL, (Sec. S.I.9) intensity dependency of the transient XES signal at 2 ps for $400 \mathrm{~nm}$ excitation, (Sec. S.I.10) fit of the XES kinetics, (Sec. S.I.11) infrared spectrum of $\left[\mathrm{Fe}(\text { terpy) })_{2}\right]^{2+}$, (Sec. S.I.12) selected structural and energetic parameters for Fe4 from DFT optimizations, and (Sec. S.I.13) complete reference list for the DFT optimizations.

\section{ACKNOWLEDGMENTS}

The authors gratefully acknowledge the European XFEL in Schenefeld, Germany, for provision of x-ray free-electron laser beamtime at FXE and would like to thank the instrument group and facility staff for their expert assistance. M.A.N. would like to thank DESY for financial support. J.W.L.W., S.D., and F.M. gratefully acknowledge financial support from the Deutsche Forschungsgemeinschaft (Grant No. SFB 1073, project B06). J.M. acknowledges financial support from the China Scholarship Council. A.K. and M.B. acknowledge financial support from the BMBF TReXHigh and PPFocus64 (Grant Nos. 05K18PPA and 05K19PP1) as well as the DFG SPP
2102 (Grant No. BA 4467/7-1). V.M. acknowledges financial support from the BMBF MatDynamics Project (No. 05K16PX1). A.G., P.Z., F.L., K.K., M.B., A.B., W.G., D.K., and C.B. acknowledge financial support from the European XFEL. W.G. acknowledges partial financial support from the National Science Centre (NCN) in Poland under SONATA BIS 6 (Grant No. 2016/22/E/ST4/00543). C.B. gratefully acknowledges financial support from the Deutsche Forschungsgemeinschaft (Grant No. SFB 925, project A4) and from the Centre for Ultrafast Imaging (CUI). S.E.C. gratefully acknowledges funding from the Helmholtz Recognition Award. The ELIALPS project (No. GINOP-2.3.6-15-2015-00001) was supported by the European Union and co-financed by the European Regional Development Fund. This work was performed, in part, at the Center for Nanoscale Materials, a U.S. Department of Energy Office of Science User Facility, and supported by the U.S. Department of Energy, Office of Science, under Contract No. DE-AC02-06CH11357.

\section{REFERENCES}

Altarelli, M., "The European x-ray free-electron laser: Toward an ultra-bright, high repetition-rate x-ray source,” High Power Laser Sci. Eng. 3, E18 (2015).

Auböck, G. and Chergui, M., "Sub-50-fs photoinduced spin crossover in $\left[\mathrm{Fe}(\mathrm{bpy})_{3}\right]^{2+}$," Nat. Chem. 7, 629-633 (2015).

Bailar, J. C., "Some problems in the stereochemistry of coordination compounds: Introductory lecture," J. Inorg. Nucl. Chem. 8, 165-175 (1958).

Bertoni, R., Cammarata, M., Lorenc, M., Matar, S. F., Létard, J.-F., Lemke, H. T., and Collet, E., "Ultrafast sight-induced spin-state trapping photophysics investigated in $\mathrm{Fe}$ (phen $)_{2}(\mathrm{NCS})_{2}$ spin-crossover crystal," Acc. Chem. Res. 48, 774-781 (2015).

Bodenthin, Y., Schwarz, G., Tomkowicz, Z., Lommel, M., Geue, T., Haase, W., Möhwald, H., Pietsch, U., and Kurth, D. G., "Spin-crossover phenomena in extended multi-component metallo-supramolecular assemblies," Coord. Chem. Rev. 253, 2414-2422 (2009).

Borshch, S. A. and Zueva, E. M., "Theoretical study of spin-state and redox multistability in an iron $[2 \times 2]$ grid complex," Eur. J. Inorg. Chem. 2013, 1009-1014 (2012).

Bowman, D. N. and Jakubikova, E., "Low-spin versus high spin ground state in pseudo-octahedral iron complexes," Inorg. Chem. 51, 6011-6019 (2012).

Bressler, C., Milne, C., Pham, V. T., ElNahhas, A., van der Veen, R. M., Gawelda, W., Johnson, S., Beaud, P., Grolimund, D., Kaiser, M., Borca, C. N., Ingold, G., Abela, R., and Chergui, M., "Femtosecond XANES study of the light-induced spin crossover dynamics in an iron (II) complex," Science 23, 489-492 (2009).

Britz, A., Abraham, B., Biasin, E., Van Driel, T., Gallo, A., Garcia-Esparza, A., Glownia, J., Loukianov, A., Nelson, S., Reinhard, M., Sokaras, D., and AlonsoMori, R., "Resolving structures of transition metal complex reaction intermediates with femtosecond EXAFS," Phys. Chem. Chem. Phys. 22, 2660 (2020).

Buhks, E., Navon, G., Bixon, M., and Jortner, J., "Spin conversion processes in solutions," J. Am. Chem. Soc. 102, 2918 (1980).

Cammarata, M., Bertoni, R., Lorenc, M., Cailleau, H., Di Matteo, S., Mauriac, C., and Collet, E., "Sequential activation of molecular breathing and bending during spin-crossover photoswitching revealed by femtosecond optical and $\mathrm{x}$-ray absorption spectroscopy," Phys. Rev. Lett. 113, 227402 (2014).

Cannizzo, A., Milne, C. J., Consani, C., Gawelda, W., Bressler, C., and Van Mourik, F., "Light-induced spin crossover in Fe (II)-based complexes: The full photocycle unraveled by ultrafast optical and x-ray spectroscopies," Coord. Chem. Rev. 254, 2677-2686 (2010).

Canton, S. E., Zhang, X., Lawson Daku, M. L., Liu, Y., Zhang, J., and Alvarez, S., "Mapping the ultrafast changes of continuous shape measures in photoexcited spin crossover complexes without long-range order," J. Phys. Chem. C 119, 3322-3330 (2015). 
Canton, S. E., Zhang, X., Lawson Daku, L. M., Smeigh, A. L., Zhang, J., Liu, Y., Wallentin, C.-J., Attenkofer, K., Jennings, G., Kurtz, C. A., Gosztola, D., Wärnmark, K., Hauser, A., and Sundström, V., "Probing the anisotropic distortion of photoexcited spin crossover complexes with picosecond x-ray absorption spectroscopy," J. Phys. Chem. C 118, 4536-4545 (2014).

Chergui, M. and Collet, E., "Photoinduced structural dynamics of molecular systems mapped by time-resolved x-ray methods," Chem. Rev. 117, 11025-11106 (2017).

Collet, E., Azzolina, G., Ichii, T., Guerin, L., Bertoni, R., Moréac, A., Cammarata, M., Daro, N., Chastanet, G., Kubicki, J., Tanaka, K., and Matar, S. F., "Lattice phonon modes of the spin crossover crystal $\left[\mathrm{Fe}(\text { phen })_{2}(\mathrm{NCS})_{2}\right]$ studied by THz, IR, Raman spectroscopies and DFT calculations," Eur. Phys. J. B 92, 12 (2019).

Galler, A., Gawelda, W., Biednov, M., Bomer, C., Britz, A., Brockhauser, S., Choi, T.-K., Diez, M., Frankenberger, P., French, M., Görries, D., Hart, M., Hauf, S., Khakhulin, D., Knoll, T., Kubicek, K., Kuster, M., Lang, P., Alves Lima, F., Schulz, S, Zalden, P., and Bressler, C., "Scientific instrument femtosecond $\mathrm{x}$-ray experiments (FXE): Instrumentation and baseline experimental capabilities," J. Synchrotron Radiat. 26, 1432-1447 (2019).

Gawelda, W., Cannizzo, A., Pham, V.-T., van Mourik, F., Bressler, C., and Chergui, M., "Ultrafast nonadiabatic dynamics of $\left[\mathrm{Fe}^{\mathrm{II}}(\mathrm{bpy})_{3}\right]^{2+}$ in solution," J. Am. Chem. Soc. 129, 8199-8206 (2007).

Gütlich, P., Hauser, A., and Spiering, H., "Thermal and optical switching of iron(II) complexes," Angew. Chem., Int. Ed. Engl. 33, 2024-2054 (1994).

Halcrow, M., Spin-Crossover Materials: Properties and Applications (Wiley Publishing, 2013)

Halder, G. J., "Guest-dependent spin crossover in a nanoporous molecular framework material," Science 298, 1762-1765 (2002).

Hauser, A., Vef, A., and Adler, P., "Intersystem crossing dynamics in Fe(II) coordination compounds," J. Chem. Phys. 95, 8710-8717 (1991).

Hauser, A., Comments Inorg. Chem. 17, 17 (1995).

Hauser, A., "Light-induced spin crossover and the high-spin $\rightarrow$ low-spin relaxation," Top. Curr. Chem. 234, 155 (2004).

Khakhulin, D., Lawson Daku, L. M., Leshchev, D., Newby, G. E., Jarenmark, M., Bressler, C., and Canton S. E., "Visualizing the coordination-spheres of photoexcited transition metal complexes with ultrafast hard x-rays," Phys. Chem. Chem. Phys. 21, 9277-9284 (2019)

Khakhulin, D., Otte, F., Biednov, M., Bömer, C., Choi, T.-K., Diez, M., Galler, A., Jiang, Y., Kubicek, K., Lima, F. A., Rodriguez-Fernandez, A., Zalden, P., Gawelda, W., and Bressler, C., "Ultrafast X-ray photochemistry at European XFEL: Capabilities of the femtosecond x-ray experiments (FXE) instrument," Appl. Sci. 10, 995 (2020).

Kirkwood, H., Letrun, R., Tanikawa, T., Liu, J., Nakatsutsumi, M., Emons, M., Jezynski, T., Palmer, T. G., Lederer, M., Bean, R. et al., "Initial observations of the femtosecond timing jitter at the European XFEL," Opt. Lett. 44, 1650-1653 (2019).

Kjær, K. S., Kunnus, K., Harlang, T. C. B., Van Driel, T. B., Ledbetter, K., Hartsock, R. W., Reinhard, M. E., Koroidov, S., Li, L., Laursen, M. G., Biasin, E., Hansen, F. B., Vester, P., Christensen, M., Haldrup, K., Nielsen, M. M., Chabera, P., Liu, Y., Tatsuno, H., and Gaffney, K. J., "Solvent control of charge transfer excited state relaxation pathways in $\left[\mathrm{Fe}\left(2,2^{\prime}\right.\right.$-bipyridine $\left.)(\mathrm{CN}) 4\right] 2^{-}$,"Phys. Chem. Chem. Phys. 20, 4238-4249 (2018).

Kjær, K. S., Van Driel, T. B., Harlang, T. C. B., Kunnus, K., Biasin, E., Ledbetter, K., Hartsock, R. W., Reinhard, M. E., Koroidov, S., Li, L., Laursen, M. G., Hansen, F. B., Vester, P., Christensen, M., Haldrup, K., Nielsen, M. M., Dohn, A. O., Pápai, M. I., Møller, K. B., and Gaffney, K. J., "Finding intersections between electronic excited state potential energy surfaces with simultaneous ultrafast x-ray scattering and spectroscopy," Chem. Sci. 10, 5749-5760 (2019).

Kroll, N., Theilacker, K., Schoknecht, M., Baabe, D., Wiedemann, D., Kaupp, M., Grohmann, A., and Hörner, G., "Controlled ligand distortion and its consequences for structure, symmetry, conformation and spin-state preferences of iron(ii) complexes," Dalton Trans. 44, 19232-19247 (2019).
Kumar, A., Kumar, P., Joshi, C., Ponnada, S., Pathak, A. K., Ali, A., Sreedhar, B. and Jain, S. L., Green Chem. 18, 2514 (2016).

Kumar, K. S. and Ruben, M., "Emerging trends in spin crossover (SCO) based functional materials and devices," Coord. Chem. Rev. 346, 176-205 (2017).

Kunnus, K., Vacher, M., Harlang, T. C. B., Kjær, K. S., Haldrup, K., Biasin, E., and Gaffney K. J., "Vibrational wavepacket dynamics in Fe carbene photosensitizer determined with femtosecond $\mathrm{x}$-ray emission and scattering," Nat. Commun. 11, 634 (2020).

Lawson Daku, L. M., Aquilante, F., Robinson, T. W., and Hauser, A., “Accurate spin-state energetics of transition metal complexes. 1. CCSD(T), CASPT2, and DFT study of $\left[\mathrm{M}(\mathrm{NCH})_{6}\right]^{2+}(\mathrm{M}=\mathrm{Fe}, \mathrm{Co})$," J. Chem. Theory Comput. 8, 42164231 (2012).

Lawson Daku, L. M. and Hauser, A., "Ab initio molecular dynamics study of an aqueous solution of $\left[\mathrm{Fe}(\mathrm{bpy})_{3}\right](\mathrm{Cl})_{2}$ in the low-spin and in the high-spin states," J. Phys. Chem. Lett. 1, 1830-1835 (2010)

Lawson Daku, L. M., Vargas, A., Hauser, A., Fouqueau, A., and Casida, M. E., "Assessment of density functionals for the high-spin/low-spin energy difference in the low-spin iron(II) tris $\left(2,2^{\prime}\right.$-bipyridine) complex," ChemPhysChem 6, 1393-1410 (2005).

Lawson Daku, L. M., "Spin-state dependence of the structural and vibrational properties of solvated iron(ii) polypyridyl complexes from AIMD simulations: Aqueous $\left[\mathrm{Fe}(\mathrm{bpy})_{3}\right] \mathrm{Cl}_{2}$, a case study," Phys. Chem. Chem. Phys. 20, 6236-6253 (2018).

Lawson Daku, L. M., "Spin-state dependence of the structural and vibrational properties of solvated iron(ii) polypyridyl complexes from AIMD simulations: II. Aqueous $\left[\mathrm{Fe}(\mathrm{tpy})_{2}\right] \mathrm{Cl}_{2}$," Phys. Chem. Chem. Phys. 21, 650-661 (2019).

Lemke, H. T., Bressler, C., Chen, L. X., Fritz, D. M., Gaffney, K. J., Galler, A., Gawelda, W., Haldrup, K., Hartsock, R. W., Ihee, H., Kim, J., Kim, K. H., Lee, J. H., Nielsen, M. M., Stickrath, A. B., Zhang, W., Zhu, D., and Cammarata, M., "Femtosecond $\mathrm{x}$-ray absorption spectroscopy at a hard $\mathrm{x}$-ray free electron laser: Application to spin crossover dynamics," J. Phys. Chem. A 117, 735-740 (2013).

Lemke, H. T, Kjær, K. S., Hartsock, R., van Driel, T. B., Chollet, M., Glownia, J. M., Song, S., Zhu, D., Pace, E., and Matar, S. F., "Coherent structural trapping through wave packet dispersion during photoinduced spin state switching," Nat. Commun. 8, 15342 (2017).

Liu, C., Zhang, J., Lawson Daku, L. M., Gosztola, D., Canton, S. E., and Zhang, X., "Probing the impact of solvation on photoexcited spin crossover complexes with high-precision $\mathrm{x}$-ray transient absorption spectroscopy," J. Am. Chem. Soc. 139, 17518-17524 (2017).

Liu, T., Zhang, Y.-J., Kanegawa, S., and Sato, O., "Photoinduced metal-to-metal charge transfer toward single-chain magnet," J. Am. Chem. Soc. 132, 82508251 (2010).

Machan, C. W., Adelhardt, M., Sarjeant, A. A., Stern, C. L., Sutter, J., Meyer, K., and Mirkin, C. A., J. Am. Chem. Soc. 134, 16921-16924 (2012).

Marchivie, M., Guionneau, P., Létard, J.-F., and Chasseau, D., "Photo-induced spin-transition: The role of the iron(II) environment distortion," Acta Crystallogr., Sect. B: Struct. Sci. 61, 25-28 (2005).

Matsumoto, T., Newton, G. N., Shiga, T., Hayami, S., Matsui, Y., Okamoto, H., Kumai, R., Murakami, Y., and Oshio, H., "Programmable spin-state switching in a mixed-valence spin-crossover iron grid," Nat. Commun. 5, 3865 (2014).

McCusker, J. K., Walda, K. N., Dunn, R. C., Simon, J. D., Magde, D., and Hendrickson, D. N., "Sub-picosecond. DELTA.S $=2$ intersystem crossing in low-spin ferrous complexes," J. Am. Chem. Soc. 114, 6919-6920 (1992).

McCusker, J. K., Walda, K. N., Dunn, R. C., Simon, J. D., Magde, D., and Hendrickson, D. N., "Subpicosecond 1MLCT. fwdarw. 5T2 intersystem crossing of low-spin polypyridyl ferrous complexes," J. Am. Chem. Soc. 115, 298-307 (1993).

Nance, J., Bowman, D. N., Mukherjee, S., Kelley, C. T., and Jakubikova, E., "Insights into the spin-state transitions in $\left[\mathrm{Fe}(\mathrm{tpy})_{2}\right]^{2+}$ : Importance of the terpyridine rocking motion," Inorg. Chem. 54, 11259-11268 (2015).

Naumova, M. A., Kalinko, A., Wong, J. W. L., Abdellah, M., Geng, H., Domenichini, E., Meng, J., Gutierrez, S. A., Mante, P.-A., Lin, W., Zalden, P., Galler, A., Lima, F., Kubicek, K., Biednov, M., Britz, A., Checchia, S., Kabanova, V., 
Wulff, M., Zimara, J., Schwarzer, D., Demeshko, S., Murzin, V., Gosztola, D., Jarenmark, M., Zhang, J., Bauer, M., Lawson Daku, M. L., Gawelda, W., Khakhulin, D., Bressler, C., Meyer, F., Zheng, K., and Canton, S. E., J. Phys. Chem. Lett. 11, 2133 (2020).

Nihei, M., Ui, M., Yokota, M., Han, L., Maeda, A., Kishida, H., Okamoto, H., and Oshio, H., "Two-step spin conversion in a cyanide-bridged ferrous square," Angew. Chem., Int. Ed. 44, 6484-6487 (2005).

Ohkoshi, S.-I., Imoto, K., Tsunobuchi, Y., Takano, S., and Tokoro, H., "Lightinduced spin-crossover magnet," Nat. Chem. 3, 564-569 (2011).

Petzold, H., Djomgoue, P., Hörner, G., Heider, S., Lochenie, C., Weber, B., and Schaarschmidt, D., "Spin state variability in $\mathrm{Fe}^{2+}$ complexes of substituted (2-(pyridin-2-yl)-1,10-phenanthroline) ligands as versatile terpyridine analogues," Dalton Trans. 46, 6218-6229 (2017).

Phan, H., Hrudka, J. J., Igimbayeva, D., Lawson Daku, L. M., and Shatruk, M., “ A simple approach for predicting the spin state of homoleptic Fe(II) tris-diimine complexes," J. Am. Chem. Soc. 139, 6437-6447 (2017).

Rodger, A. and Johnson, B. F. G., "Which is more likely: The Ray-Dutt twist or the Bailar twist?,” Inorg. Chem. 27, 3061-3062 (1988).

Ruben, M., Rojo, J., Romero-Salguero, F. J., Uppadine, L. H., and Lehn, J.M., "Grid-type metal ion architectures: Functional metallosupramolecular arrays," Angew. Chem., Int. Ed. Engl. 43, 3644-3662 (2004).

Schäfer, B., Greisch, J.-F., and Faus, I., "Divergent coordination chemistry: Parallel synthesis of $[2 \times 2]$ iron(II) grid-complex tauto-conformers," Angew. Chem., Int. Ed. Engl. 55, 10881-10885 (2016).

Schneider, B., Demeshko, S., Dechert, S., and Meyer, F., "A double-switching multistable $\mathrm{Fe}_{4}$ grid complex with stepwise spin-crossover and redox transitions," Angew. Chem., Int. Ed. 49, 9274-9277 (2010).

Schneider, B., Demeshko, S., Neudeck, S., Dechert, S., and Meyer, F., "Mixed-spin [2 $\times 2$ 2] $\mathrm{Fe}_{4}$ grid complex optimized for quantum cellular automata," Inorg. Chem. 52, 13230-13237 (2013).

Shen, F., Huang, W., Wu, D., Zheng, Z., Huang, X.-C., and Sato, O., "Redox modulation of spin crossover within a cobalt metallogrid," Inorg. Chem. 55, 902-908 (2015).

Smeigh, A. L., Creelman, M., Mathies, R. A., and McCusker, J. K., "Femtosecond time-resolved optical and Raman spectroscopy of photoinduced spin crossover: Temporal resolution of low-to-high spin optical switching," J. Am. Chem. Soc. 130, 14105-14107 (2008).

Steinert, M., Schneider, B., Dechert, S., Demeshko, S., and Meyer, F., "Spinstate versatility in a series of $\mathrm{Fe}_{4}[2 \times 2]$ grid complexes: Effects of counteranions, lattice solvent, and intramolecular cooperativity," Inorg. Chem. 55, 2363-2373 (2016).

Stock, P., Deck, E., Hohnstein, S., Korzekwa, J., Meyer, K., Heinemann, F. W., Breher, F., and Hörner, G., "Molecular spin crossover in slow motion: Lightinduced spin-state transitions in trigonal prismatic iron(II) complexes," Inorg. Chem. 55(11), 5254-5265 (2016).

Stock, P., Pędziński, T., Spintig, N., Grohmann, A., and Hörner, G., "High intrinsic barriers against spin-state relaxation in iron(II)-complex solutions," Chem. Eur. J. 19, 839-842 (2012).

Stock, P., Spintig, N., Scholz, J., Epping, J. D., Oelsner, C., Wiedemann, D., Grohmann, A., and Hörner, G., "Spin-state dynamics of a photochromic iron(II) complex and its immobilization on oxide surfaces via phenol anchors," J. Coord. Chem. 68, 3099-3115 (2017a).

Stock, P., Wiedemann, D., Petzold, H., and Hörner, G., "Structural dynamics of spin crossover in iron(II) complexes with extended-tripod ligands," Inorganics 5, 60 (2017b).

Tschentscher, T., Bressler, C., Grünert, J., Madsen, A., Mancuso, A., Meyer, M., Scherz, A., Sinn H., and Zastrau, U., "Photon beam transport and scientific instruments at the European XFEL,” Appl. Sci. 7, 592 (2017).

Uppadine, L. H., Gisselbrecht, J.-P., and Lehn, J.-M., "Protonic modulation of redox properties in ionisable $[2 \times 2]$ grid-like metalloarrays," Chem. Commun. 6, 718-719 (2004).

van der Vlugt, J. I., Demeshko, S., Dechert, S., and Meyer, F., “Tetranuclear $\mathrm{Co}^{\mathrm{II}}, \mathrm{Mn}^{\mathrm{II}}$, and $\mathrm{Cu}^{\mathrm{II}}$ complexes of a novel binucleating pyrazolate ligand preorganized for the self-assembly of compact [ $2 \times 2$ ]-grid structures," Inorg Chem. 47, 1576-1585 (2008).

Vankó, G., Bordage, A., Pápai, M., Haldrup, K., Glatzel, P., March, A. M., and Gawelda, W., "Detailed characterization of a nanosecond-lived excited state: X-ray and theoretical investigation of the quintet state in photoexcited $\left.[\text { Fe(terpy })_{2}\right]^{2+}, " J$. Phys. Chem. C 119, 5888-5902 (2015).

Vanquickenborne, L. G. and Pierloot, K., "Role of spin change in the stereomobile reactions of strong-field d6 transition-metal complexes," Inorg. Chem. 20, 3673-3677 (1981).

Vargas, A., Krivokapic, I., Hauser A., and Lawson Daku, L. M., “Towards accurate estimates of the spin-state energetics of spin-crossover complexes within density functional theory: A comparative case study of cobalt(ii) complexes," Phys. Chem. Chem. Phys. 15, 3752 (2013).

Wang, Y.-T., Li, S.-T., Wu, S.-Q., Cui, A.-L., Shen, D.-Z., and Kou, H.-Z., "Spin transitions in $\mathrm{Fe}(\mathrm{II})$ metallogrids modulated by substituents, counteranions, and solvents," J. Am. Chem. Soc. 135, 5942-5945 (2013).

Wolf, M. M. N., Groß, R., Schumann, C., Wolny, J. A., Schünemann, V., Døssing, A., and Diller, R., "Sub-picosecond time resolved infrared spectroscopy of high-spin state formation in Fe(ii) spin crossover complexes," Phys. Chem. Chem. Phys. 10, 4264 (2008).

Wu, D. Y., Sato, O., Einaga, Y., and Duan, C. Y., "A spin-crossover cluster of iron(II) exhibiting a mixed-spin structure and synergy between spin transition and magnetic interaction," Angew. Chem., Int. Ed. 48, 1475-1478 (2009).

Zerdane, S., Cammarata, M., Balducci, L., Bertoni, R., Catala, L., Mazerat, S., Mallah, T., Pedersen, M. N., Wulff, M., Nakagawa, K., Tokoro, H., Ohkoshi, S.-I., and Collet, E., "Probing transient photoinduced charge transfer in Prussian blue analogues with time-resolved XANES and optical spectroscopy," Eur. J. Inorg. Chem. 2018, 272-277 (2018a).

Zerdane, S., Cammarata, M., Iasco, O., Boillot, M.-L., and Collet, E., "Photoselective MLCT to d-d pathways for light-induced excited spin state trapping," $J$ Chem. Phys. 151, 171101 (2019).

Zerdane, S., Collet, E., Dong, X., Matar, S. F., Wang, H. F., Desplanches, C., and Cammarata, M., "Electronic and structural dynamics during the switching of the photomagnetic complex $\left[\mathrm{Fe}\left(\mathrm{L}_{222} \mathrm{~N}_{5}\right)(\mathrm{CN})_{2}\right]$," Chem. - Eur. J. 24, 50645069 (2018b).

Zerdane, S., Wilbraham, L., Cammarata, M., Iasco, O., Rivière, E., Boillot, M.-L., Ciofini, I., and Ciofini, E., "Comparison of structural dynamics and coherence of d-d and MLCT light-induced spin state trapping," Chem. Sci. 8, 4978-4986 (2017).

Zhang, W., Alonso-Mori, R., Bergmann, U., Bressler, C., Chollet, M., Galler, A., and Gaffney, K. J., "Tracking excited-state charge and spin dynamics in iron coordination complexes," Nature 509, 345-348 (2014).

Zhang, W. and Gaffney, K. J., "Mechanistic studies of photoinduced spin crossover and electron transfer in inorganic complexes," Acc. Chem. Res. 48, 1140-1148 (2015).

Zhang, W., Kjær, K. S., Alonso-Mori, R., Bergmann, U., Chollet, M., Fredin, L. A., Hadt, R. G., Hartsock, R. W., Harlang, T., Kroll, T., Kubiček, K., Lemke, H. T., Liang, H. W., Liu, Y., Nielsen, M. M., Persson, P., Robinson, J. S., Solomon, E. I., Sun, Z., Sokaras, D., van Driel, T. B., Weng, T.-C., Zhu, D., Wärnmark, K., Sundström, V., and Gaffney, K. J., "Manipulating charge transfer excited state relaxation and spin crossover in iron coordination complexes with ligand substitution," Chem. Sci. 8, 515-523 (2017).

Zhang, X., Lawson Daku, M. L., Zhang, J., Suarez-Alcantara, K., Jennings, G., Kurtz, C. A., and Canton, S. E., "Dynamic Jahn-Teller effect in the metastable high-spin state of solvated $\left[\mathrm{Fe}(\text { terpy })_{2}\right]^{2+}, " J$. Phys. Chem. C 119, 3312-3321 (2015).

Zhang, Y., Li, D., Clérac, R., Kalisz, M., Mathonière, C., and Holmes, S. M. "Reversible thermally and photoinduced electron transfer in a cyano-bridged $\left\{\mathrm{Fe}_{2} \mathrm{Co}_{2}\right\}$ square complex," Angew. Chem., Int. Ed. 49, 3752-3756 (2010).

Zueva, E. M., Ryabikh, E. R., Kuznetsov, A. M., and Borshch, S. A., "Spin crossover in tetranuclear cyanide-bridged iron(II) square complexes: A theoretical study," Inorg. Chem. 50, 1905-1913 (2011). 